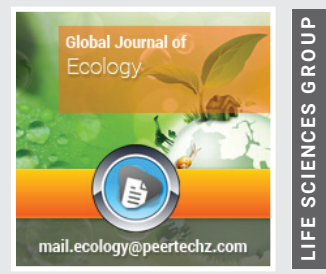

\title{
Development of Stages of the Implementation of the Environmental Monitoring
} Program

\author{
Rahimova NA, Abdullayev VH* and Abbasova VS
}

Deputy Director General at SOCAR Energy, Georgia

Received: 18 February, 2020

Accepted: 09 May, 2020

Published: 11 May, 2020

*Corresponding author: Abdullayev VH, Deputy Director General at SOCAR Energy, Georgia, E-mail: abdulvugar@mail.ru

Keywords: Environmental information systems; Geographic and environmental data processing; Environmental monitoring; Geographic information systems (GIS)

https://www.peertechz.com

Check for updates

\begin{abstract}
The object of the research is environmental monitoring, which allows to present the current situation about the environment. The monitoring program aims to gather information for the decision-making process. This article describes environmental monitoring and highlights its main goals and objectives. This article describes the properties of the environmental monitoring object. The main components of environmental monitoring are also considered here. The database and analytical dataprocessing tools are main components of environmental monitoring. In addition, this article considers the structure of environmental monitoring. Next, environmental monitoring functions were considered. This article also provided a classification of monitoring systems. One problem is the development of the most appropriate algorithm for implementing environmental monitoring. The article is devoted to the development of software modules of environmental information systems that perform geographic and environmental data processing. There are software modules designed for centralized operation of data (data entry, editing, deleting, etc.), the conceptual types of GIS, the goals and functions of environmental monitoring, and these are taken into account in the existing system. The monitoring system should also have a good search tool, which is also described in this article. The search tool is described using SQL and Delphi. The research used decision-making methods. This article describes the stages of development of an environmental monitoring program. The research identified the inputs and outputs of the environmental monitoring programme, as well as its objects and the relationship between them. The results obtained in the future will be useful for improving the decision-making of authorized persons.
\end{abstract}

\section{Introduction}

The monitoring program is focused on solving a specific problem and decisions are made based on the information obtained. The main task of the monitoring program is to collect detailed and reliable information on the environmental state of the object under investigation. The appropriate decisionmaking process is going from top to bottom. The initial information is integrated as it moves from the bottom level to the top and enters the top phase in a generalized form. These decisions become more concrete as they move from top to bottom [1]. The goals and objectives of the monitoring program are divided into the following areas:

1) Collection of information related to the problem;

2) Description of information on various monitoring areas;

3) Selection of alternative solutions aimed at improving the situation or achieving the goal [2].
The next step defines the parameters and priorities of the monitored object. The object here refers to areas subjected to various anthropogenic impacts. For example, if the purpose of the monitoring program is related to the environmental condition of the sea (or object), then the selection of the impact site will be determined by the access routes or natural streams of any enterprise. No, if the problem characterizes the general state of the environment in the contaminated areas (district, city, etc.), then the environment, water, land, etc. will be prioritized for monitoring. can be removed. After the control parameters are selected, the locations, numbers, and coordinates of the sampling points are determined. By selecting methods of analysis and equipment (ph-meters, chromotograph, gas analyzer, etc.), environmental factors are identified using visual methods. Appropriate measuring devices can be used at this stage $[3,4]$.

One of the main components of environmental monitoring is sampling points. To this end, special sampling stations are being 
established at observation points. After sampling, laboratory tests are performed to determine its physical, physicalchemical and ecotoxicological parameters [5]. Documentation of the results is entrusted to the monitoring person. After the monitoring, an authorized person shall draw up an appropriate act. After the ingredients are analyzed, the preliminary results are compared with the results obtained and placed in the log of the laboratory. The results are being interpreted to ensure long-term retention of the analyzes. Interpretation - forms a description of objects or situations according to the observed data. At the same time, they are explained by describing the monitoring situation [6]. Regular relationships between the properties of the objects are detected and these laws are used to reveal new information. Based on the discovery of irregular relationships between the characteristics, the correct results are realized. There is a great need for modern data technology, because manual data analysis presents a number of difficulties to classify results (data) over the years. Information system are used for this purpose, and the results of monitoring and data from their analysis are posted on the database [7].

The concept of a database that is the basis of information technology is one of the important areas of scientific and technical development. Widespread use of GIS (geographic information systems) technologies is also currently being used in environmental monitoring [8].

Recently, the environmental impact assessment has been designed to automate analyzes of environmental monitoring tools, and present complex and multifunctional aspects. Environmental information systems have the potential to expose environmental problems from large and small distances to monitoring environmental quality, to accurately identify the source of environmental problems and to make predictions of development. Remote sensing technologies, satellites and even mobile phones help ecologists to monitor and manage the environment, reduce emissions and increase energy efficiency. The creation of such systems is based on a combination of complex data and knowledge that can be difficult to organize [9].

The relevance of research is based on the need to determine the level of environmental pollution. Thus, the object the research has chosen environmental monitoring to allow the collection of the necessary data. The aim of the research is to develop an environmental monitoring program. To do this, define the main environmental objects and the relationships between them, the input and output data used in the system.

\section{Methods of research}

Environmental monitoring is a hierarchical structure, complex observation method, and is a system for assessing and predicting changes in the environment as a result of anthropogenic effects of the ecosystem. As it turns out, the environmental monitoring system incorporates information (monitoring) and management components. There is a direct and opposite information communication between the elements of the system. Such information relationships improve the overall management process and simplify the decision-making process to address the overall situation [10].

\section{Environmental monitoring system:}

- Information on the state of the environment.

- Observation and information on the causes of the event.

- It should collect, systematize and analyze the information on the implementation of the objectives based on permissible normative data.

- Management is organized for adaptive management of monitoring activities. With the management function, the environmental system interprets the current situation, predicts the future, diagnoses the causes of the problem, forms a plan to address them, and monitors the implementation of the plan.

To determine the goals and objectives of environmental monitoring of the Caspian Sea, it is necessary to eliminate serious environmental problems arising during economic activity and minimize their negative impact on the environment. For this purpose the following steps are being implemented:

- Conducting monitoring studies for the rational use, restoration, protection and conservation of natural resources of the Caspian Sea, ensuring environmental safety in this area, and conservation of biodiversity;

- Defining environmental criteria for the protection of the water environment and the use of natural resources to ensure the right of the population to live in a normal environmental environment;

- Monitoring and forecasting of environmentally sound impacts on the use of natural resources.

Depending on the nature of the problem to be solved, the type of environment, sources and factors influencing the environment, monitoring systems are classified as shown in the following Table 1.

\begin{tabular}{|c|c|c|c|}
\hline $\begin{array}{l}\text { Impact sources monitoring } \\
\text { Impact sources }\end{array}$ & \multicolumn{3}{|c|}{$\begin{array}{l}\text { Impact sources monitoring } \\
\text { Impact sources }\end{array}$} \\
\hline \multirow{2}{*}{$\begin{array}{l}\text { Impact factor monitoring } \\
\text { Impact factors }\end{array}$} & \multicolumn{3}{|c|}{$\begin{array}{l}\text { Impact factor monitoring } \\
\text { Impact factors }\end{array}$} \\
\hline & Physical & Biological & Chemistry \\
\hline \multirow{2}{*}{$\begin{array}{l}\text { Monitoring of the biosphere } \\
\text { environment } \\
\text { Environment }\end{array}$} & \multicolumn{3}{|c|}{$\begin{array}{c}\text { Monitoring of the biosphere environment } \\
\text { Environment }\end{array}$} \\
\hline & Atmosphere & $\begin{array}{l}\text { The } \\
\text { ocean }\end{array}$ & $\begin{array}{l}\text { Rivers, lakes, } \\
\text { groundwater }\end{array}$ \\
\hline
\end{tabular}

Based on the results of the functional composition of the monitoring of the marine ecological condition and methodological analysis of observations, the objectives within the defined function are achieved. The prediction of the functional state of the system is determined by the experts on the prerequisites, and the evaluation procedure for the purpose of the function is performed. The task under this procedure is to analyze the general functions affecting the system, and to formulate unique and alternative solutions. 
A number of standard methods for environmental assessment have been developed. These methods allow for the right formation of decision-making by professionals based on collective experience. The assessment tools currently used include checklists, matrices, networks, measuring devices, geographic information and expert systems.

\section{Research results and discussion}

One of the key issues in information systems is the efficient search of data in the database. The system explored user requirements to implement a search engine for fuzzy queries and took into account requests made by them. In order to meet the needs of different users, the system has developed various queries and suitable search methods for processing these requests. The search methods proposed for the processing of queries are implemented in accordance with the requirements of individual users. Processing of queries is done using SQL and filtering procedures in Delphi environment. The use of logical and computational operations here allows you to perform complex structured queries and increase the completeness and accuracy of information retrieval.

The system is primarily regulated, that is, its frequency and content are predefined, requests are processed. The search for information is conducted according to certain criteria. Examples of such criteria include zone name, object name, output name, sample history, type of object. To make it easier to answer these queries, users are provided with structured lists, tables, and diagrams. The results are obtained using the interactive interface in the interactive mode. Below are the functions of some surveys, their implementation algorithms, and fragments from the results of the surveys.

In the system, the search for the fuzzy query is performed based on the algorithm shown in Figure 1. According to this algorithm, complete information about what types of ingredients are discharged into the sea at specific facilities and the qualitative and quantitative characteristics of these ingredients can be obtained in tables, histograms and reports.

The SELECT procedure uses WHERE instructions to select not all entries but only those that meet certain conditions. Consider the following filtering inquiries:

SELECT Thickness, Solid, Thickness

FROM «Zona.DB» Zone, «Object.DB» Object, «Chixish. DB» Chikish, «Iller.DB» Iller, «Numune.DB» Numune, «Solids.DB»

$$
\begin{aligned}
& \text { WHERE (Zona.Z_ad = 'Baku-Absheron') } \\
& \text { and (Object.Ob_ad = 'Sand Island Node') } \\
& \text { and (Chixish.Ch_ad = 'well 1851') } \\
& \text { and (Iller.Num_il = 2018) } \\
& \text { and (Numune.Num_test }=11.02 .2020) .
\end{aligned}
$$

Using this kind of survey, the Baku-Absheron zone selects the «Sand Island OGPI» and the «1851 well» into the facility. According to the selected speech, dated 11.02.2020, the tables are linked through the keywords, and the contents of the table are displayed on the screen. In the course of the survey, the prices of the search fields can be entered by the user from the ready lists and keyboards. To complete the algorithm, the $\mathrm{Zo}$ ne $\rightarrow$ Object $\rightarrow$ Output $\rightarrow$ Sample $\rightarrow$ Injection Chain is executed using a procedure that generates a request and generates a request.

Thus, by using the search mode to respond to any query, the user will be able to get the required queries.

\section{Conclusions}

Based on information analysis of the subject area, a geographical database structure has been established, and a

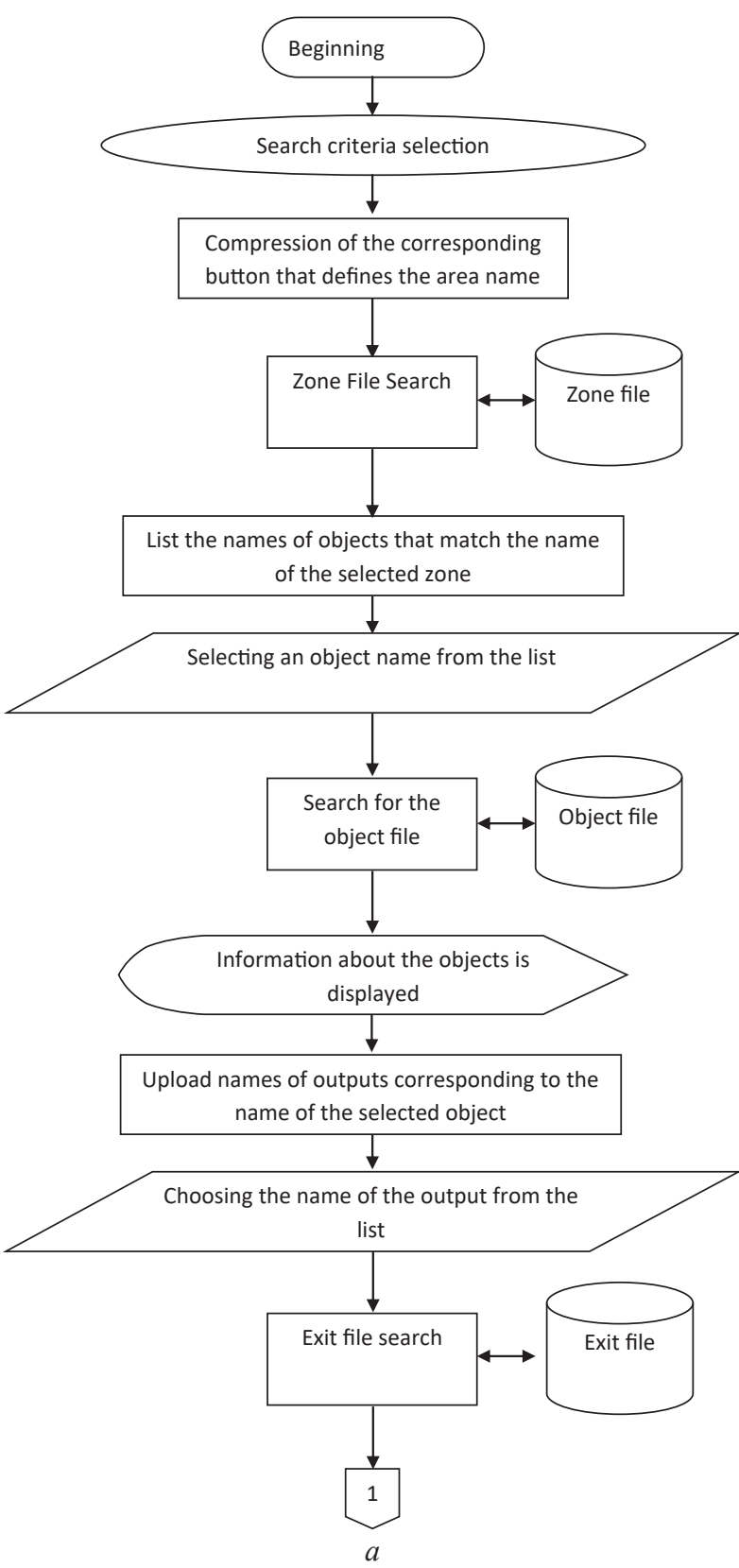

Figure 1a: Algorithm of information retrieval system: a - Part 1; b - Part 2; c - Part 


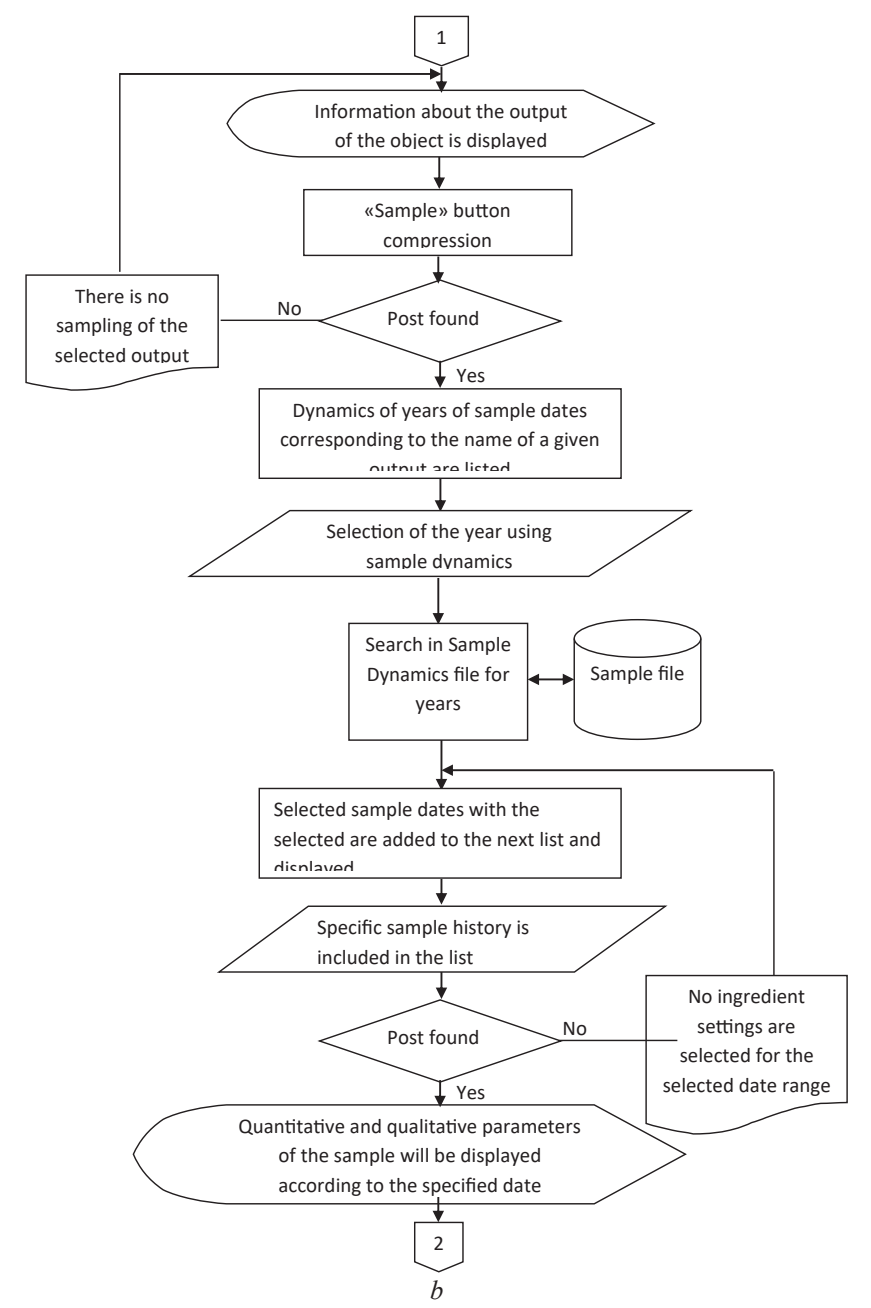

Figure 1b: Algorithm of information retrieval system: $a$ - Part 1; $b$ - Part 2; c - Part 3.

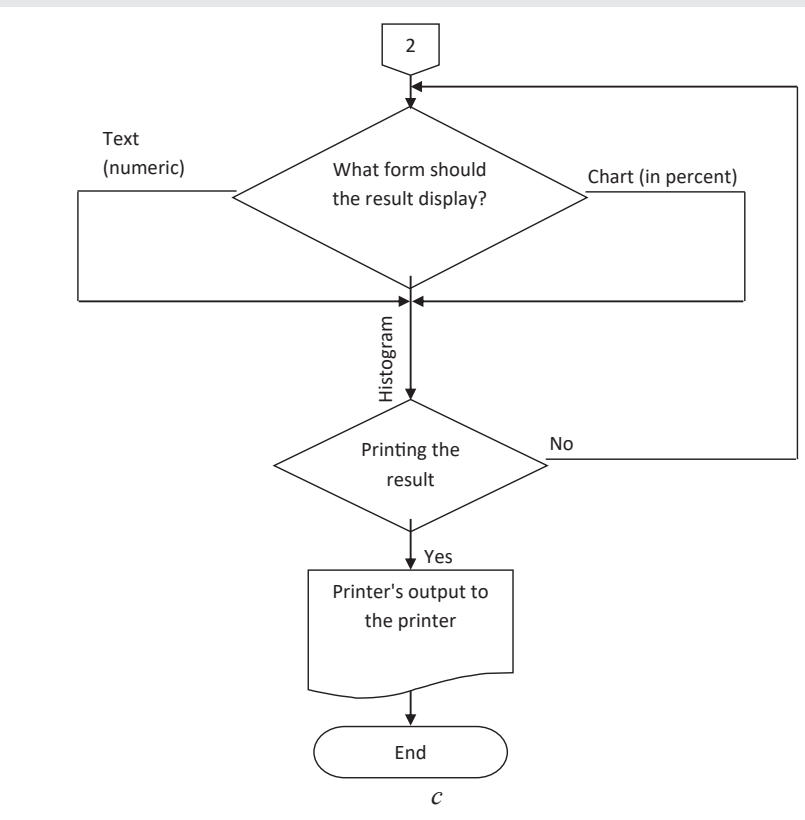

Figure 1c: Algorithm of information retrieval system: a - Part 1; $b$ - Part 2; - Part 3.

Copyright: ๑ 2020 Rahimova NA, et al. This is an open-access article distributed under the terms of the Creative Commons Attribution License, which permits unrestricted use, distribution, and reproduction in any medium, provided the original author and source are credited. database has been established based on documents collected for environmental monitoring. Considered the development of an environmental monitoring system with the help of GIS and algorithms for data description. The results obtained in the future will be useful for improving the quality of environmental monitoring.

\section{References}

1. Biber E (2013). The Challenge of Collecting and Using Environmental Monitoring Data. Ecol Soc 18: 68. Link: https://bit.ly/3b9Kj10

2. Sanga C, Fue K, Kilima F (2012) Project Monitoring and Evaluation Information System: Case study of EPINAV programme. Link: https://bit.ly/2Y J95mN

3. Heink U, Kowarik I (2010) What are indicators? On the definition of indicators in ecology and environmental planning. Ecological Indicators 10: 584-593. Link: https://bit.ly/2L9Tzsd

4. Turnhout E (2009) The effectiveness of boundary objects: the case of ecological indicators. Sci Public Policy 36: 403-412. Link: https://bit.ly/2WfmnGg

5. Wadhia K, Thompson KC (2007) Low-cost ecotoxicity testing of environmental samples using microbiotests for potential implementation of the Water Framework Directive. TrAC Trends in Analytical Chemistry 26: 300-307. Link: https://bit.ly/3dluUNk

6. Watson ID, Siodmiak J, Oosterhuis WP, Corberand J, Jorgensen PE, et al. (2015) European views on patients directly obtaining their laboratory test results. Clin Chem Lab Med 53: 1961-1966. Link: https://bit.ly/3be9eRO

7. Domínguez F, Dauwe S, Cuong NT, Cariolaro D, Touhafi A, et al. (2014) Towards an Environmental Measurement Cloud: Delivering Pollution Awareness to the Public. Int J Distrib Sens Netw 10: 541360. Link: https://bit.ly/35HLp3D

8. Mierzejowska A, Zogala M (2018) The characteristics of geographical information systems in terms of their current use. Journal of Water and Land Development 39: 101-108. Link: https://bit.ly/2SN8mNB

9. Bender A, Francisco F, Sundberg J (2017) A Review of Methods and Models for Environmental Monitoring of Marine Renewable Energy. 12th European Wave and Tidal Energy Conference (EWTEC 2017), Cork, Ireland 1-10. Link: https://bit.ly/3biLyMa

10. Kupschus S, Schratzberger M, Righton D (2016) Practical implementation of ecosystem monitoring for the ecosystem approach to management. J App Ecol 53: 1236-1247. Link: https://bit.ly/2WEPiSS based on the proposed models, information retrieval methods 